\title{
Human Alveolar Macrophages Produce a Fibroblast-like Collagenase and Collagenase Inhibitor
}

\author{
Howard G. Welgus, Edward J. Campbell, Zvi Bar-Shavit, Robert M. Senior, and Steven L. Teitelbaum \\ Division of Dermatology and Respiratory and Critical Care Division, Department of Medicine and Department of Pathology, \\ Jewish Hospital of St. Louis at Washington University Medical Center; and Division of Cell Biology, \\ Washington University School of Dental Medicine, St. Louis, Missouri 63110
}

\begin{abstract}
Human macrophages have been implicated in connective tissue remodeling; however, little is known about their direct effects upon collagen degradation. We now report that human alveolar macrophages in culture produced both a collagenase and a collagenase inhibitor. The collagenase was secreted in latent form and could be activated by exposure to trypsin. Collagenase production could be increased three- to fourfold by incubating the cells with lipopolysaccharide, but synthesis was largely unaffected by exposure to phorbol myristate acetate. By several criteria, macrophage collagenase was the same as the collagenase secreted by human skin fibroblasts: (a) they were antigenically indistinguishable in double immunodiffusion; $(b)$ both degraded type III collagen preferentially to type I, had little activity against type II collagen, and none against types IV and $V$, and (c) their affinity for susceptible collagens was equivalent, Michaelis constant $=1-2 \mu \mathrm{M}$. Collagenase inhibitory activity was also present in the macrophage-conditioned medium, and was accounted for by an antigen that showed immunologic and functional identity with the collagenase inhibitor secreted by human skin fibroblasts. The amount of inhibitor released by unstimulated cells, $\sim 100 \mathrm{ng} / 10^{6}$ cells per $24 \mathrm{~h}$, was substantially augmented by both phorbol and lipopolysaccharide, although considerable variability in response to these agents was observed between macrophage populations derived from different subjects. As negligible quantities of collagenase or collagenase inhibitor were detectable intracellularly, it appeared that both proteins were secreted rapidly after synthesis. Thus, human macrophages have the capacity to modulate collagen degradation directly by production of collagenase and collagenase inhibitor.
\end{abstract}

\section{Introduction}

Collagenase catalyzes the initial and rate-limiting step of collagen degradation (1-3). Accordingly, collagenases occupy a crucial position in normal collagen turnover and the maintenance of proper connective tissue architecture. Elevated collagenase activity has been associated with disorders such as rheumatoid arthritis (4) and periodontal disease (5), and results in excessive tissue destruction.

Collagenases have been isolated from a number of mam-

Dr. Bar-Shavit is an Arthritis Foundation Investigator. Address reprint requests to Dr. Welgus, Division of Dermatology.

Received for publication 31 December 1984.

J. Clin. Invest.

(c) The American Society for Clinical Investigation, Inc. $0021-9738 / 85 / 07 / 0219 / 06 \quad \$ 1.00$

Volume 76, July 1985, 219-224 malian connective tissue cells (6-10) and inflammatory cells (11-15), including macrophages. A collagenase secreted by human skin fibroblasts has been purified to homogeneity (7), biochemically characterized (16), and studied in regard to enzyme kinetics $(2,3,17)$, biosynthesis (18), and mechanisms of activation (19). Human skin fibroblasts also secrete a collagenase inhibitor of $M_{\mathrm{r}} 28,500(20,21)$ that inhibits the enzyme with a 1:1 stoichiometry via the formation of a highaffinity (inhibition constant $\left[K_{\mathrm{i}}\right]=10^{-10} \mathrm{M}$ ) enzyme-inhibitor complex (22).

Although human macrophages participate in immune and inflammatory reactions in which tissue remodeling may occur, relatively little is known concerning their direct influence upon collagen turnover. Preliminary evidence has suggested that human alveolar macrophages secrete collagenase activity against type I and III collagens that is unaffected by phagocytosis of particles or immune complexes (23). Human sputum contains a collagenase directed against type $\mathrm{V}$ collagen (24). The cell producing this enzyme is not known, but rabbit alveolar macrophages have been shown to release a type $\mathrm{V}$ collagenase (13).

We now report that human alveolar macrophages in culture produce collagenase and collagenase inhibitor that are immunologically and functionally identical to the collagenase and collagenase inhibitor elaborated by human skin fibroblasts. Lipopolysaccharide (LPS) ${ }^{1}$ leads to a substantial increase in collagenase production, which is often accompanied by a parallel elevation in collagenase inhibitor secretion, whereas phorbol myristate acetate (PMA) appears to selectively stimulate inhibitor biosynthesis, with little or no change in collagenase production. These findings indicate that macrophages may directly influence the turnover of collagen at sites of inflammation.

\section{Methods}

Reagents. Tris base, bovine serum albumin, bovine pancreatic trypsin, soybean trypsin inhibitor (SBTI), phenylmethylsulfonylfluoride (PMSF), EDTA, LPS, and PMA were obtained from Sigma Chemical Co. (St. Louis, MO). All other chemicals were reagent grade.

Alveolar macrophages. Alveolar macrophages were harvested from healthy young adult volunteers by saline bronchoalveolar lavage (25). To ensure an adequate cell yield, only cigarette smokers ( $>1$ pack/d) were selected. The cells obtained were $>95 \%$ macrophages as determined on Wright-stained cytocentrifuge preparations. The remaining cells were primarily lymphocytes; fibroblasts were not observed. The lavaged cells were washed in Hanks' balanced salt solution (HBSS) and plated in flat-bottom tissue culture dishes (35 mm diam) at $2.75 \times 10^{6}$ cells/

1. Abbreviations used in this paper: ELISA, enzyme-linked immunosorbent assay; $k_{\text {cat }}$, catalytic rate; LPS, lipopolysaccharide; PMA, phorbol myristate acetate; PMSF, phenylmethylsulfonylfluoride; SBTI, soybean trypsin inhibitor. 
well per $\mathrm{ml}$ of HBSS. After $1 \mathrm{~h}$ at $37^{\circ} \mathrm{C}$ in air, the HBSS was exchanged for bicarbonate-buffered minimal essential medium containing $4 \mathrm{mg}$ / $\mathrm{ml}$ bovine serum albumin. Some cultures also contained $30 \mu \mathrm{g} / \mathrm{ml}$ LPS or $10 \mathrm{ng} / \mathrm{ml}$ PMA. The cells were then maintained in humidified $95 \%$ air and $5 \% \mathrm{CO}_{2}$ at $37^{\circ} \mathrm{C}$.

Cell-conditioned medium. Conditioned medium was removed every $24 \mathrm{~h}$ and replaced with fresh medium. After its removal, the conditioned medium was adjusted to $0.05 \mathrm{M}$ Tris, $0.01 \mathrm{M} \mathrm{CaCl}_{2}, \mathrm{pH}$ 7.5. For certain studies of functional collagenase or inhibitor activity, conditioned medium was dialyzed overnight against $0.005 \mathrm{M}$ Tris, $0.001 \mathrm{M} \mathrm{CaCl}_{2}$, $\mathrm{pH} 7.5$, then lyophilized and resuspended in water to achieve a 10fold concentration.

Purification of human skin fibroblast collagenase and collagenase inhibitor. Both collagenase and collagenase inhibitor were purified to homogeneity from the serum-containing medium of confluent normal human skin fibroblast cultures as described previously $(7,20)$.

Activation of macrophage and fibroblast procollagenases. Latent collagenase was activated by the addition of trypsin at $25^{\circ} \mathrm{C}$ for 10 min (7). A range of trypsin concentrations, usually $0.5-2.5 \mu \mathrm{g}$ per 50$\mu l$ sample, was used to ensure maximal activation. An eightfold molar excess of SBTI was then added to prevent further tryptic activity.

Collagenase and collagenase inhibitor assays. Collagenase was assayed at $37^{\circ} \mathrm{C}$ in $0.05 \mathrm{M}$ Tris, $0.01 \mathrm{M} \mathrm{CaCl}_{2}, \mathrm{pH} 7.5$, using reconstituted $\left[{ }^{14} \mathrm{C}\right]$ glycine-labeled guinea pig type I collagen fibrils $(25,000$ $\mathrm{cpm} / \mathrm{mg}$ [26]) as substrate. The solubilized products were quantified in a scintillation counter.

To determine collagenase inhibitor activity, concentrated macrophage medium was treated with EDTA $(20 \mathrm{mM})$ to destroy any intrinsic enzyme, exhaustively dialyzed, and then assayed for capacity to inhibit pure fibroblast collagenase $(7,21)$. The molar stoichiometry of inhibition was quantified by calculating moles of collagenase inhibited by macrophage medium per mole immunoreactive protein, determined using an enzyme-linked immunosorbent assay (ELISA) for fibroblast collagenase inhibitor (21).

Collagen substrate specificity. Collagen specificity was assessed by densitometric measurements on polyacrylamide gels of the $3 / 4$-length $\mathrm{TC}^{\mathrm{A}}$ products of collagenase digestion (3). Values for the Michaelis constant $\left(K_{\mathrm{m}}\right)$ and catalytic rate $\left(k_{\text {cat }}\right)$ were obtained by expressing the data as a Lineweaver-Burk plot. Since the macrophage medium was a crude preparation, the calculated velocity represents a relative rate. Human collagen types I, III, and V from placenta and type II collagen from cartilage were provided by Dr. R. E. Burgeson, Shriner's Hospital, Portland, OR. Human type IV collagen was a gift from Dr. H. Sage, University of Washington, Seattle, WA. Inhibition profile assays were performed using 1,10-phenanthroline (1 mM), EDTA (20 mM), PMSF $(1 \mathrm{mM})$, SBTI $(1 \mathrm{mg} / \mathrm{ml})$, and iodoacetic acid $(1 \mathrm{mM})$.

Immunologic assays. ELISAs for human fibroblast collagenase (27) and collagenase inhibitor (21) were performed upon cell-conditioned medium and cell extracts. Extracts were prepared by scraping the cell layer into $1 \mathrm{ml}$ of buffer $\left(0.05 \mathrm{M}\right.$ Tris, $\left.0.01 \mathrm{M} \mathrm{CaCl}_{2}, \mathrm{pH} 7.5\right)$, followed by sonication and centrifugation $(2,500 \mathrm{~g}$ for $20 \mathrm{~min})$. Gel diffusion was performed in $1.0 \%$ Ionagar (28).

Metabolic labeling and immunoprecipitation of collagenase and collagenase inhibitor. The metabolic labeling and immunoprecipitation procedures for collagenase and collagenase inhibitor were the same, except the former utilized labeling with $\left[{ }^{35} \mathrm{~S}\right]$ methionine (New England Nuclear, Boston, MA), and the latter $\left[{ }^{35}\right.$ S $]$ cysteine (New England Nuclear). Macrophages were exposed to methionine-free or cysteinefree medium containing the appropriate labeled amino acid (50-100 $\mu \mathrm{Ci} / \mathrm{ml}$ of medium) for $24 \mathrm{~h} .150 \mu \mathrm{l}$ of pulsed medium was then incubated with $5 \mu \mathrm{l}$ of either specific or preimmune antibody at $4^{\circ} \mathrm{C}$ overnight in a total reaction volume of $300 \mu \mathrm{l}$ (buffer $=0.04 \mathrm{M}$ sodium phosphate, pH 8.0 , containing $0.15 \mathrm{M} \mathrm{NaCl}, 0.1 \%$ Triton X-100, 1 $\mathrm{mM}$ PMSF). To precipitate the labeled protein, IgGsorb (The Enzyme Center, Inc., Malden, MA) was added for $1 \mathrm{~h}$ at $4^{\circ} \mathrm{C}$, after which the immunoprecipitates were washed extensively, and then dissolved in $100 \mu$ l of sample buffer containing $0.0625 \mathrm{M}$ Tris- $\mathrm{HCl}(\mathrm{pH} \mathrm{6.8)}, 8 \mathrm{M}$ urea, and 3\% sodium dodecyl sulfate. After boiling, the samples were subjected to polyacrylamide gel electrophoresis (29), the slab gels equilibrated with En $^{3}$ Hance (New England Nuclear) for $1.5 \mathrm{~h}$, rinsed in cold distilled water for $1 \mathrm{~h}$, and then dried under vacuum. The dried gels were exposed to Kodak XAR-5 X-Omat AR film (Eastman Kodak Co., Rochester, NY) at $-70^{\circ} \mathrm{C}(30)$.

Other assays. Protein concentrations were determined spectrophotometrically by the method of Groves et al. (31) with bovine serum albumin as a standard. Collagen content was determined by hydroxyproline assay (32).

\section{Results}

Collagenase. Alveolar macrophages were obtained from three volunteer smokers by saline bronchoalveolar lavage and placed in culture as described under Methods. Unconcentrated conditioned medium derived from the macrophages of one such individual, which was collected between 24 and $48 \mathrm{~h}$ of incubation, possessed significant collagenolytic activity (Fig. 1 $A$, J.M.). Activity was detectable in medium obtained from

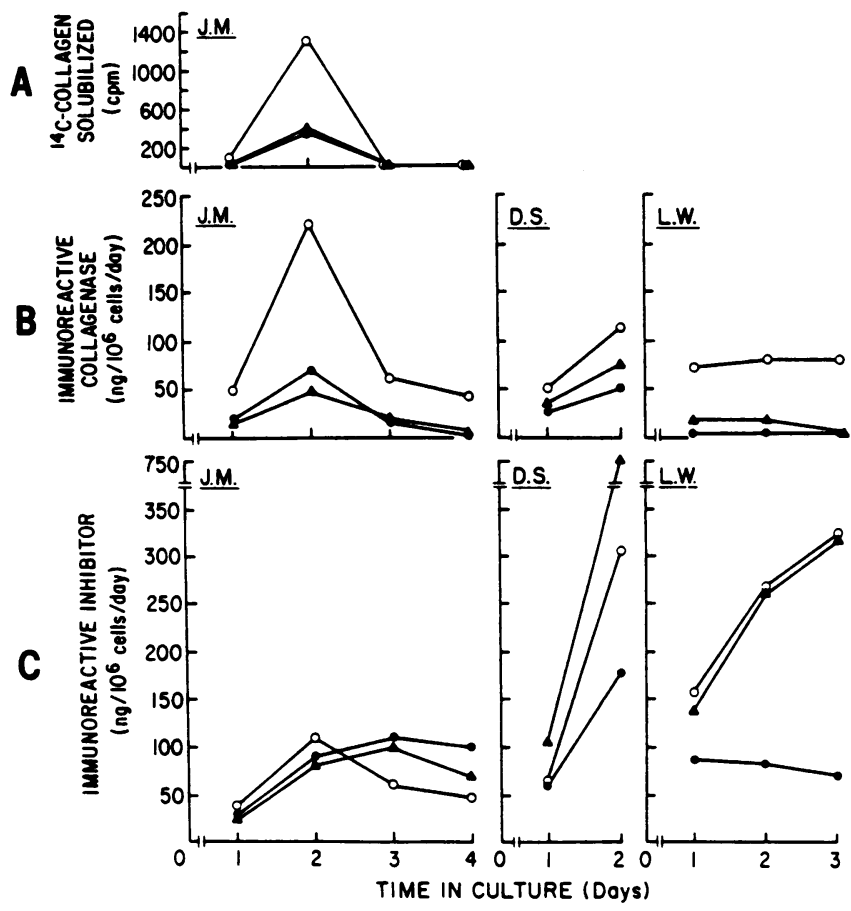

Figure 1. Collagenase and collagenase inhibitor released by human alveolar macrophages in culture. Macrophages were obtained from three volunteer smokers by saline bronchoalveolar lavage and placed in culture as detailed under Methods. Each vertical set of panels represents assays performed using conditioned medium derived from the cultured alveolar macrophages of a single subject (J.M., D.S., or L.W.). $(A)$ Collagenase activity. Solubilization of ${ }^{14} \mathrm{C}$-labeled collagen fibrils by $100-\mu l$ aliquots of unconcentrated conditioned medium (trypsin activated) was measured after overnight incubation at $37^{\circ} \mathrm{C}$ : •, serum-free medium; o, serum-free medium plus LPS (30 $\mu \mathrm{g} / \mathrm{ml})$; $\triangle$, serum-free medium plus PMA $(10 \mathrm{ng} / \mathrm{ml})$. Conditioned medium from subjects D.S. and L.W. displayed no apparent enzyme activity under any culture conditions employed. The solubilization of 1,000 cpm of ${ }^{14} \mathrm{C}$-collagen represents $0.033 \mathrm{U}$ (micrograms collagen per minute at $37^{\circ} \mathrm{C}$ ) of collagenase activity. $(B)$ Immunoreactive collagenase. Medium was assayed using the ELISA for human fibroblast collagenase (27). (C) Immunoreactive collagenase inhibitor. Medium was assayed using the ELISA for human fibroblast collagenase inhibitor (21). 
both unstimulated cells and cells incubated with either LPS (30 $\mu \mathrm{g} / \mathrm{ml})$ or PMA (10 $\mathrm{ng} / \mathrm{ml}$ ); however, exposure to LPS, but not PMA, resulted in catalytic activity three- to fourfold greater than observed in medium from unstimulated cells. Greater than $90 \%$ of the collagenase in culture medium was latent, and required limited proteolysis with trypsin for catalytic function. The collagenolytic activity was abolished by 1,10 phenanthroline or EDTA, whereas PMSF, SBTI, and iodoacetic acid were without effect (not shown).

The collagenase in conditioned medium cleaved monomeric type I, II, and III collagens in a manner characteristic of mammalian collagenases. At $25^{\circ} \mathrm{C}$, only a single $3 / 4: 1 / 4$ cleavage was observed, producing typical 3/4-length $\mathrm{TC}^{\mathrm{A}}$ and 1/4-length $\mathrm{TC}^{\mathrm{B}}$ fragments (not shown). In contrast, type IV and $\mathrm{V}$ collagens were not susceptible substrates. The $K_{m}$ s of 1-2 $\mu \mathrm{M}$ against the different collagen types (Table I) were virtually identical to values observed with fibroblast collagenase (3). Since macrophage collagenase has not been purified, values for $k_{\text {cat }}$ could not be calculated; however, the relative susceptibilities of type I, II, and III collagens to degradation paralleled those of its fibroblast counterpart. Monomeric type III collagen was cleaved 14-fold faster than type $I$ and 600 -fold more rapidly than type II.

Macrophage-conditioned medium, derived from cells of the same individual which produced measurable collagenolytic activity (J.M.), was then subjected to the ELISA for fibroblast collagenase. As shown in Fig. $1 B$, immunoreactive protein exactly paralleled functional collagenase activity. The extent of immunologic similarity between the macrophage and fibroblast collagenases was further evident in gel diffusion. Employing antibody to fibroblast collagenase, a precipitin line of complete identity was observed between crude macrophage medium and pure fibroblast enzyme (Fig. 2). Furthermore, this antibody abolished all the type I collagenolytic activity present in macrophage medium (not shown).

The immunologic identity of macrophage-derived collagenase to human fibroblast collagenase was used to examine enzyme production in macrophage-conditioned medium obtained from cells of the two individuals (D.S. and L.W.) which failed to elaborate demonstrable collagenolytic activity. Em-

Table I. Comparison of the Collagen Specificity of Macrophage and Skin Fibroblast Collagenases

\begin{tabular}{lrcc}
\hline Enzyme source & Collagen type & $K_{\mathrm{m}}$ & $\begin{array}{c}\text { Relative rate } \\
\text { of cleavage } \pm\end{array}$ \\
\hline Macrophage & I & $\mu M$ & \\
& II & 1.1 & 41.2 \\
& III & 1.7 & 1.0 \\
& & 1.9 & 598 \\
Skin fibroblast* & I & & \\
& II & 0.8 & 53.4 \\
& III & 2.1 & 1.0 \\
& & 1.4 & 565
\end{tabular}

\pm , from Lineweaver-Burk plots (see Methods). The rate of human type II cleavage by macrophage-conditioned medium has been arbitrarily set equal to 1.0. There was no detectable activity against collagen types IV and V using either enzyme source.

* Values shown are actual catalytic rates from Welgus et al. (3).

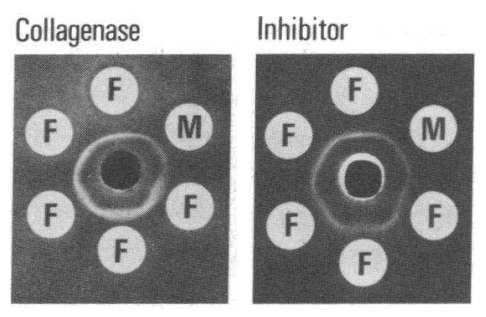

Figure 2. Immunologic comparisons of collagenase and collagenase inhibitor derived from human alveolar macrophages versus human skin fibroblasts. Concentrated conditioned medium from LPS-stimulated macrophages (subject D.S.)

was compared in gel diffusion with pure fibroblast collagenase (7) and pure fibroblast collagenase inhibitor (20). Collagenase: $F$, pure fibroblast collagenase; $\mathbf{M}$, macrophage medium; antibody to fibroblast collagenase is contained in the center well. Inhibitor: F, pure fibroblast collagenase inhibitor; M, macrophage medium; antibody to fibroblast inhibitor is contained in the center well.

ploying the ELISA for fibroblast collagenase, medium from the unstimulated cells of one patient (D.S.) contained measurable quantities of immunoreactive protein. Cells from both patients responded to exposure to LPS with a significant increase in immunoreactive material released into culture medium, whereas exposure to phorbol produced little or no effect (Fig. $1 B$, D.S., L.W.). The stimulation of collagenase production by LPS reflected an increase in the synthesis of new enzyme protein, as demonstrated by biosynthetic labeling with $\left[{ }^{35} \mathrm{~S}\right]$ methionine and subsequent immunoprecipitation using specific collagenase antibody (Fig. 3). Under any tested condition, however, collagenase activity in medium conditioned by these two subjects' cells could not be detected due to the presence of a molar excess of a collagenase inhibitor simultaneously secreted by such macrophages (Fig. $1 C$, D.S., L.W., see below).

Collagenase inhibitor. The same conditioned media examined for collagenase activity and immunoreactivity was tested in an ELISA using antibody to human fibroblast collagenase inhibitor (21). Macrophage-conditioned medium from the unstimulated cells of all three individuals contained an amount of immunoreactive material approximating $100 \mathrm{ng} /$ $10^{6}$ cells per $24 \mathrm{~h}$ (Fig. $1 \mathrm{C}$ ). Expression of inhibitor was stimulated in the cells of two subjects (D.S., L.W.) two- to fourfold by exposure to LPS, while PMA produced a fourfold enhancement in inhibitor levels (Fig. $1 C$, D.S., L.W.). The effect of PMA was directly upon inhibitor synthesis, as shown by a parallel increase in immunoprecipitable material after the addition of $\left[{ }^{35} \mathrm{~S}\right]$ cysteine to culture medium (Fig. 3). Macrophages derived from the third individual (J.M.) were not stimulated by either LPS or PMA to produce increased quantities of inhibitor (Fig. $1 C$, J.M.). To further characterize this immunoreactivity, medium was concentrated and examined by double immunodiffusion. A line of complete identity was observed between the macrophage medium and pure fibroblast collagenase inhibitor using antibody directed against the fibroblast protein (Fig. 2). The functional identity of the immunoreactive material was established by its inhibition of fibroblast collagenase activity. Based on the amount of immunoreactive material in concentrated macrophage medium, a 1:1 molar stoichiometry of inhibition was observed with respect to enzyme (Fig. 4).

To test the hypothesis that macrophage-derived collagenase and collagenase inhibitor are secretory proteins, intracellular vs. extracellular levels of both were compared (Table II). No appreciable intracellular storage of either protein was found, 


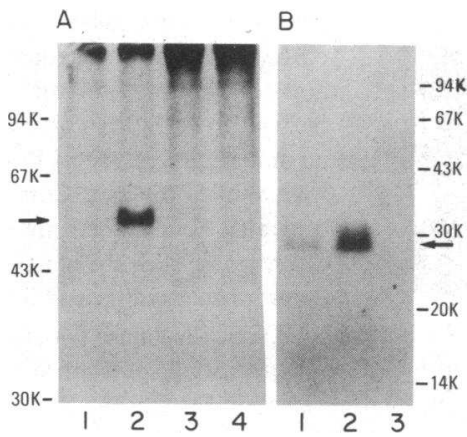

Figure 3. Immunoprecipitation of metabolically labeled macrophage-derived collagenase and collagenase inhibitor. Macrophages (from L.W.) were exposed to either $\left.{ }^{35} \mathrm{~S}\right]$ methionine (collagenase) or [ $\left.{ }^{35} \mathrm{~S}\right]$ cysteine (inhibitor) for $24 \mathrm{~h}$ and the medium processed as detailed under Methods. (A) Collagenase: 1, LPStreated cells plus preimmune IgG; 2, LPS

treated cells plus specific collagenase antibody; 3 , untreated cells plus specific collagenase antibody; 4 , untreated cells plus preimmune IgG. The arrow denotes the migration position of pure human fibroblast collagenase. $(B)$ Collagenase inhibitor: 1 , untreated cells plus specific inhibitor antibody; 2, phorbol-treated cells plus specific inhibitor antibody; 3, phorbol-treated cells plus preimmune IgG. The arrow denotes the migration position of pure human fibroblast collagenase inhibitor. Molecular weight markers are positioned as indicated in the margins (e.g., 94K, 94,000 mol wt).

which suggested that their biologic role is to modulate collagen turnover in the extracellular matrix.

\section{Discussion}

These studies demonstrate that human alveolar macrophages produce two substances in vitro that directly affect collagen degradation, collagenase, and collagenase inhibitor. The first of these products was an antigen immunologically identical to human skin fibroblast collagenase, the quantity of which paralleled collagenase activity. The catalytic properties of the macrophage-produced enzyme were also very similar to fibroblast collagenase (3), as manifested by its collagen type specificity and affinity $\left(1 / K_{m}\right)$ for monomeric collagen substrates.

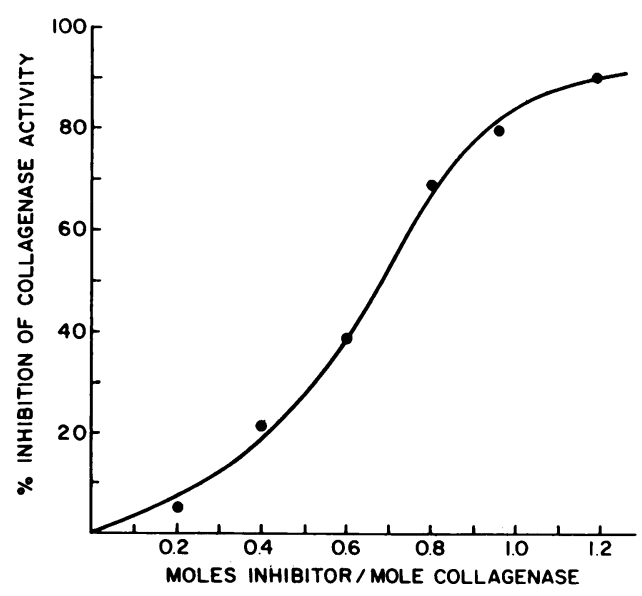

Figure 4. Molar stoichiometry of collagenase inhibition by macrophage collagenase inhibitor. Inhibition of exogenously added fibroblast collagenase by concentrated macrophage medium was quantified as described under Methods. The amount of macrophage inhibitor was determined using the ELISA for human fibroblast collagenase inhibitor (21).
Macrophage-conditioned medium also contained collagenase inhibitory activity, reflecting the presence of an antigen immunologically identical to the collagenase inhibitor secreted by human skin fibroblasts. The amount of inhibitor released in unstimulated cultures was $\sim 100 \mathrm{ng} / 10^{6}$ cells per $\mathrm{d}$, as compared with $\sim 700 \mathrm{ng} / 10^{6}$ cells per $d$ found in confluent skin fibroblast cultures (21). The inhibitor's functional activity also matched that of its fibroblast-derived counterpart. It should be emphasized that the presence of collagenase inhibitor in culture medium markedly affects observed collagenolytic activity. Indeed, in macrophage-conditioned medium using cells derived from two of the individuals in this study, collagenase was demonstrable only by immunologic techniques (Figs. 1 and 3); functional enzyme activity was completely obscured by an excess of collagenase inhibitor concomitantly released into the culture medium. Therefore, immunologic assessments of both enzyme and inhibitor are crucial to adequately understand the potential mechanisms by which macrophages regulate collagen turnover.

As observed with nonhuman macrophages (11), LPS produced a severalfold increase in collagenase secretion by human alveolar macrophages. This effect was mediated via the synthesis of new enzyme, as demonstrated by immunoprecipitation of metabolically labeled collagenase (Fig. 3). Exposure of macrophages to PMA resulted in little, if any, augmentation of collagenase production. Collagenase inhibitor was also secreted in detectable quantities by unstimulated cells. In the case of inhibitor production, however, considerable variability in response to exogenously added LPS and PMA was evident in macrophage populations derived from different individuals. Cells from two patients (D.S. and L.W.) were induced to augment their inhibitor synthesis severalfold upon exposure to LPS or PMA; macrophages from one individual (J.M.) failed to respond to either of these agents. As observed for collagenase, the increase in inhibitor levels reflected the synthesis of new inhibitor protein, demonstrable by immunoprecipitation techniques after the addition of $\left[{ }^{35} \mathrm{~S}\right]$ cysteine to culture medium (Fig. 3). The data thus suggest that the expression of collagenase and collagenase inhibitor may occur in a coordinate manner in response to an agent such as LPS; yet, another substance such as PMA can clearly enhance inhibitor secretion with little or no effect on collagenase levels (Fig. 1). Therefore, collagenase and collagenase inhibitor production are not necessarily regulated in tandem and may vary depending upon exposure to specific chemical agents. In any event, both macrophage collagenase and collagenase inhibitor appear to function in a secretory capacity; neither protein is accumulated intracellularly to a significant extent (Table II).

The collagenase and collagenase inhibitors derived from fibroblasts and macrophages are structurally and functionally distinct from the analogous molecules of human neutrophils $(14,15,33)$. Neutrophil collagenase preferentially cleaves monomeric type I collagen as compared with type III (I/III $>10 ;[34])$, whereas macrophage-derived collagenase exhibits the opposite specificity (III/I $>10$; Table I). The neutrophil collagenase inhibitor functions via a thiol-disulfide exchange mechanism (33), while agents such as mersalyl and oxidized glutathione do not affect fibroblast (20) or macrophage inhibitor activity (not shown). Furthermore, neutrophil extracts do not react immunologically with fibroblast collagenase inhibitor (20). 
Table II. Intracellular and Extracellular Macrophage Collagenase and Macrophage Collagenase Inhibitor

\begin{tabular}{|c|c|c|c|c|}
\hline & \multicolumn{2}{|c|}{ Collagenase } & \multicolumn{2}{|c|}{ Inhibitor } \\
\hline & $\begin{array}{l}\text { Intra- } \\
\text { cellular }\end{array}$ & $\begin{array}{l}\text { Extra- } \\
\text { cellular }\end{array}$ & $\begin{array}{l}\text { Intra- } \\
\text { cellular }\end{array}$ & $\begin{array}{l}\text { Extra- } \\
\text { cellular }\end{array}$ \\
\hline & $\mu g$ & $\mu g$ & $\mu g$ & $\mu g$ \\
\hline Control & 0.00 & 1.00 & 0.12 & 1.42 \\
\hline LPS & 0.03 & 3.06 & 0.10 & 1.03 \\
\hline PMA & 0.07 & 0.67 & 0.14 & 1.20 \\
\hline
\end{tabular}

Extracellular collagenase and collagenase inhibitor are the total amounts of each protein secreted into medium by $10^{7}$ macrophages between 24 and $48 \mathrm{~h}$ in culture. Intracellular levels represent the quantity of each protein contained in the cell layer after $48 \mathrm{~h}$ in culture. Macrophages were obtained from subject J.M. (Fig. 1).

The role of the macrophage in collagen turnover extends beyond its capacity to secrete collagenase and collagenase inhibitor. Macrophages are a source of mediators such as interleukin-1 and prostaglandins (35), of structural macromolecules such as fibronectin (36), and of proteinase inhibitors such as $\alpha$-2-macroglobulin (37), all of which may influence collagen metabolism. Our study indicates, however, that human macrophages have the direct capacity to modulate collagen turnover. The results also indicate an avenue for the study of macrophage-mediated collagenolysis, since sensitive probes are presently available for this collagenolytic system.

\section{Acknowledgments}

We gratefully acknowledge the technical assistance of Ms. Nadean Brown and Ms. Catherine Fliszar, and express our appreciation to Ms. Linda Winston for the preparation of this manuscript.

This work was supported by U. S. Public Health Service grants AM35805 (Dr. Welgus) and AM32788 (Dr. Teitelbaum), and National Heart, Lung, and Blood Institute grants HL30341 (Dr. Campbell) and HL29594 (Dr. Senior) from the National Institutes of Health. Dr. Welgus is a recipient of Research Career Development Award AM01525.

\section{References}

1. Gross, J., and Y. Nagai. 1965. Specific degradation of the collagen molecule by tadpole collagenolytic enzyme. Proc. Natl. Acad. Sci. USA. 54:1197-1204.

2. Welgus, H. G., J. J. Jeffrey, G. P. Stricklin, W. T. Roswit, and A. Z. Eisen. 1980. Characteristics of the action of human skin fibroblast collagenase on fibrillar collagen. J. Biol. Chem. 255:6806-6813.

3. Welgus, H. G., J. J. Jeffrey, and A. Z. Eisen. 1981. The collagen substrate specificity of human skin fibroblast collagenase. J. Biol. Chem. 256:9511-9515.

4. Harris, E. D., Jr., J. M. Evanson, D. R. DiBona, and S. M. Krane. 1970. Collagenase and rheumatoid arthritis. Arthritis Rheum. 13:83-94.

5. Birkedal-Hansen, H. 1980. Collagenase in periodontal disease. In Collagenase in Normal and Pathological Connective Tissues. D. E. Woolley and J. M. Evanson, editors. J. Wiley and Sons, New York. 128-140.

6. Harris, E. D., Jr., and S. M. Krane. 1974. Collagenases. N. Engl. J. Med. 291:557-563, 605-609, 652-661.
7. Stricklin, G. P., E. A. Bauer, J. J. Jeffrey, and A. Z. Eisen. 1977. Human skin collagenase: isolation of precursor and active forms from both fibroblast and organ cultures. Biochemistry. 16:1607-1615.

8. Johnson-Muller, B., and J. Gross. 1978. Regulation of corneal collagenase production: epithelial-stromal cell interactions. Proc. Natl. Acad. Sci. USA. 75:4417-4421.

9. Cawston, T. E., G. Murphy, E. Mercer, W. A. Galloway, B. L. Hazleman, and J. J. Reynolds. 1983. The interaction of purified rabbit bone collagenase with purified rabbit bone metalloproteinase inhibitor. Biochem. J. 211:313-318.

10. Nagase, H., R. C. Jackson, C. E. Brinckerhoff, C. A. Vater, and E. D. Harris, Jr. 1983. A precursor form of latent collagenase produced in a cell-free system with mRNA from rabbit synovial cells. J. Biol. Chem. 256:11951-11954.

11. Wahl, L. M., S. M. Wahl, S. E. Mergenhagen, and G. R. Martin. 1974. Collagenase production by endotoxin-activated macrophages. Proc. Natl. Acad. Sci. USA. 71:3598-3601.

12. Werb, Z., and S. Gordon. 1975. Secretion of a specific collagenase by stimulated macrophages. J. Exp. Med. 142:346-360.

13. Mainardi, C. L., J. M. Seyer, and A. H. Kang. 1980. Typespecific collagenolysis: a type $\mathrm{V}$ collagen-degrading enzyme from macrophages. Biochem. Biophys. Res. Commun. 97:1108-1115.

14. Macartney, H. W., and H. Tschesche. 1983. Latent and active human polymorphonuclear leukocyte collagenases. Eur. J. Biochem. 130:71-78.

15. Hasty, K. A., M. S. Hibbs, A. H. Kang, and C. L. Mainardi. 1984. Heterogeneity among human collagenases demonstrated by monoclonal antibody that selectively recognizes and inhibits human neutrophil collagenase. J. Exp. Med. 159:1455-1463.

16. Stricklin, G. P., A. Z. Eisen, E. A. Bauer, and J. J. Jeffrey. 1978. Human skin fibroblast collagenase: chemical properties of precursor and active forms. Biochemistry. 17:2331-2337.

17. Welgus, H. G., R. E. Burgeson, J. A. M. Wootton, R. R. Minor, C. Fliszar, and J. J. Jeffrey. 1985. Degradation of monomeric and fibrillar type III collagens by human skin collagenase: kinetic constants using different animal substrates. J. Biol. Chem. 260:10521059.

18. Valle, K.-J., and E. A. Bauer. 1979. Biosynthesis of collagenase by human skin fibroblasts in monolayer culture. J. Biol. Chem. 254: 10115-10122.

19. Stricklin, G. P., J. J. Jeffrey, W. T. Roswit, and A. Z. Eisen. 1983. Human skin procollagenase: mechanisms of activation by organomercurials and trypsin. Biochemistry. 22:61-68.

20. Stricklin, G. P., and H. G. Welgus. 1983. Human skin fibroblast collagenase inhibitor: purification and biochemical characterization. $J$. Biol. Chem. 258:12252-12258.

21. Welgus, H. G., and G. P. Stricklin. 1983. Human skin fibroblast collagenase inhibitor: comparative studies in human connective tissues, serum, and amniotic fluid. J. Biol. Chem. 258:12259-12264.

22. Welgus, H. G., J. J. Jeffrey, A. Z. Eisen, W. T. Roswit, and G. P. Stricklin. Human skin fibroblast collagenase: interaction with substrate and collagenase inhibitor. Collagen Relat. Res. In press.

23. Gadek, J., G. Hunninghake, R. Zimmerman, and R. Crystal. 1981. Production of connective tissue-specific proteases by human alveolar macrophages is constitutive (non-regulatable). Am. Rev. Respir. Dis. 123:55a. (Abstr.)

24. Rich, E. A., J. M. Seyer, A. H. Kang, and C. L. Mainardi. 1983. Identification of a type $\mathrm{V}$ collagen-degrading enzyme from human sputum. Am. Rev. Respir. Dis. 128:166-169.

25. Senior, R. M., E. J. Campbell, and B. Villiger. 1981. Obtaining and culturing alveolar macrophages. In Methods for Studying Mononuclear Phagocytes. D. A. Adams, H. Koren, and P. Edelson, editors. Academic Press, Inc., New York. 69-83.

26. Nagai, Y., C. M. Lapiere, and J. Gross. 1966. Tadpole collagenase: preparation and purification. Biochemistry. 5:3123-3130.

27. Cooper, T. W., E. A. Bauer, and A. Z. Eisen. 1982. Enzyme- 
linked immunosorbent assay for human skin collagenase. Collagen Relat. Res. 3:205-216.

28. Ouchterlony, O. 1958. Diffusion-in-gel methods for immunological analysis. Prog. Allergy. 5:1-78.

29. King, J., and U. K. Laemmli. 1971. Polypeptides of the tail fibres of bacteriophage T4. J. Mol. Biol. 62:465-477.

30. Lasky, R. A., and A. D. Mills. 1975. Quantitative film detection of ${ }^{3} \mathrm{H}$ and ${ }^{14} \mathrm{C}$ in polyacrylamide gels by fluorography. Eur. J. Biochem. $56: 335-341$.

31. Groves, W. E., F. C. Davis, Jr., and B. Sells. 1968. Spectrophotometric determination of microgram quantities of protein without nucleic acid interference. Anal. Biochem. 22:195-210.

32. Bergmann, I., and R. Loxley. 1963. Two improved and simplified methods for the spectrophotometric determination of hydroxyproline. Anal. Chem. 35:1961-1965.

33. Macartney, H. W., and H. Tschesche. 1983. The collagenase inhibitor from human polymorphonuclear leukocytes. Eur. J. Biochem. 130:79-83.

34. Horwitz, A. L., A. J. Hance, and R. G. Crystal. 1977. Granulocyte collagenase: selective digestion of type I relative to type III collagen. Proc. Natl. Acad. Sci. USA. 74:897-901.

35. Mizel, S. B., J.-M. Dayer, S. M. Krane, and S. E. Mergenhagen. 1981. Stimulation of rheumatoid synovial cell collagenase and prostaglandin production by partially purified lymphocyte-activating factor (interleukin I). Proc. Natl. Acad. Sci. USA. 78:2474-2477.

36. Villiger, B., D. G. Kelley, W. Engelman, C. Kuhn III, and J. A. McDonald. 1981. Human alveolar macrophage fibronectin: synthesis, secretion, and ultrastructural localization during gelatincoated latex particle binding. J. Cell Biol. 90:711-720.

37. White, R., A. Janoff, and H. P. Godfrey. 1980. Secretion of alpha-2-macroglobulin by human alveolar macrophages. Lung. 158:914. 